\title{
Infection and low back pain: seeking evidence or fear of exploring new indications for antibiotics?
}

\author{
Majid Artus $^{1} \cdot$ Jeremy Fairbank $^{2} \cdot$ Matthew Scarborough $^{3} \cdot$ Nadine Foster $^{1}$
}

Received: 1 March 2016/Revised: 1 March 2016/Accepted: 1 March 2016/Published online: 14 March 2016

(C) Springer-Verlag Berlin Heidelberg 2016

Infection in the spine might be the cause of symptoms in a group of patients with severe chronic low back pain (LBP). What about the large body of research recommending biopsychosocial management? Where have we heard a similar story before? Well, Helicobacter pylori infection as the cause of indigestion was a major challenging discovery that led to a paradigm shift in managing that condition which had hitherto been managed mainly through symptomatic and psychological approaches, and sometimes major surgery. The similarities between these stories are uncanny-not least in the challenges facing attempts to establish the clear evidence.

So what are the challenges that face proving the principle of infection theory in LBP? Following the Koch's postulates linking infection and a disease state [1], we have to demonstrate that an infectious agent is present. Intact intervertebral discs are avascular and sterile but pathogens have been identified in herniated and degenerated discs since the 1970s [2, 3]. Compared to the stomach, access to intervertebral discs is difficult and sampling carries a high risk of contamination from the skin. This is particularly relevant as the most common pathogens isolated are Propionibacterium acnes and coagulase negative Staphylococci, both common skin commensals. Two recent reviews

Majid Artus

m.artus@keele.ac.uk

1 Research Institute for Primary Care and Health Sciences, Keele University, Keele, UK

2 Nuffield Department of Orthopaedics, Rheumatology and Musculoskeletal Sciences, University of Oxford, Windmill Road, Headington, Oxford, UK

3 Oxford University Hospitals NHS Foundation Trust, Oxford, UK conclude that micro-organisms are found in about $35 \%$ of surgically removed discs, and that $P$. acnes is the most frequently identified species $[4,5]$. When samples are taken from the vertebral body rather than from the disc, no evidence of bacteria can be found [6].

In 1987, particular signs or changes seen on magnetic resonance imaging (MRI) of the spine were described for the first time [7], Michael Modic then classified them into three types with distinct radiological and histological features [8]. Type 1 Modic changes correspond to bone oedema of the vertebral endplate; type 2 fatty degeneration and type 3 end-stage sclerosis. These changes are thought to be caused by inflammatory mediators in the adjacent herniated or degenerated discs triggered by infection in these discs. In other words, these changes could be biomarkers for disc infection. An important link in this developing chain is establishing whether Modic changes are associated with symptoms of LBP. Several studies evidence such an association [4, 5, 9-12] and provide prevalence estimates in LBP patients that vary widely, from $0.5 \%$ [13] to $62 \%$ [14] depending on study design, setting and inclusion criteria. A consensus seems to suggest that type 1 changes in particular are associated with symptoms of LBP $[9-11,15]$ and their prevalence in LBP patients ranges from 12 to $24 \%$.

Based on this evidence, a randomised controlled trial (RCT) (162 participants) from Denmark investigated the effectiveness of antibiotics for hospital patients with severe chronic LBP with type 1 Modic changes [16]. It showed that co-amoxiclav $(500 / 125 \mathrm{mg}$ tablets, three times a day for 100 days) was better than placebo (effect size of 0.3 on RMDQ at end of 100 days of treatment and 1.0 at 12 months). The finding received much international attention. A replication RCT on 71 participants has since been published [17] and showed similar results. At least 
three other replication RCTs among hospital patients with LBP and Modic changes are underway [18-20].

Given the low virulence of the organisms identified, the question remains as to whether the organisms are truly responsible for causing symptoms. It clearly is not possible to obtain direct evidence of a causal association through the deliberate inoculation of healthy human discs with pathogens, as was done with $H$. pylori, although an animal model is feasible and probably being considered. Similarly, it is not feasible to perform repeated disc biopsies and culture on individual patients undergoing therapy. We therefore have to seek circumstantial evidence, for example by testing an alternative class of antibiotic, thereby making a non-antibiotic effect less likely, or by culturing disc material obtained from surgically treated patients either before or after antibiotic therapy or placebo. A trial designed with this objective in mind would allow either confirmation or rejection of two of Koch's postulates.

So where does all of this leave us on the path of assessing the potential for a paradigm shift in managing chronic LBP? The evidence is incomplete and even with the results of the ongoing RCTs it will remain incomplete, for the following reasons. Both of the published [16, 17] and planned trials [18-20] rely on Modic changes as the biomarker for response to antibiotics, and all have used the same broad spectrum antibiotic. This leaves a number of important questions unanswered: (1) what is the association between Modic changes, infection and LBP? The evidence on this is not beyond doubt, as only a small number of studies that isolated bacteria in intervertebral discs examined Modic changes [4, 5]; (2) are Modic changes the only marker to identify potential treatment responders?; (3) are the antibiotics used in trials on LBP unnecessarily broad spectrum? If $P$. acnes is the main pathogen, there is no theoretical advantage to be gained by using co-amoxiclav as compared to benzyl penicillin or other similarly narrow spectrum agent. With the current rising risk of antibiotic resistance caused by their inappropriate use [21, 22], it is even more important to ensure a judicious assessment of the evidence before wider implementation in clinical practice. Research is also needed that tests the role of Modic changes and other MRI findings and of simpler clinical features from patients' symptoms and signs that might identify responders to antibiotics. In particular, identifying clinical markers could provide a much more cost-effective approach, compared with MRI scans, with greater utility in primary care where most chronic LBP patients are managed.

Despite these important gaps in the evidence, investigators in several countries have found it very difficult to secure funding for research that addresses these gaps-in the UK we know of four unsuccessful applications. The lack of evidence-based patient selection and clear treatment protocols has led to a growing tide of clinicians resorting to ad hoc use of antibiotics, encouraged by an increasingly frustrated patient population. Given the prevalence of chronic LBP, its societal impact and the limited benefit from current treatments, robust testing of this potentially revolutionary intervention is merited. We ask research funders for courage in their decision-making to help us decide whether or not this pig can fly.

\section{Compliance with ethical standards}

Conflict of interest None.

\section{References}

1. Koch R (1876) Untersuchungen über Bakterien: V. Die Ätiologie der Milzbrand-Krankheit, begründet auf die Entwicklungsgeschichte des Bacillus anthracis (Investigations into bacteria: V. The etiology of anthrax, based on the ontogenesis of Bacillus anthracis) (PDF). Cohns Beitrage zur Biologie der Pflanzen (in German)

2. Newman JH, Mitchell RG (1975) Diphtheroid infection of the cervical spine. Acta Orthop Scand 46:67-70

3. Noble RC, Overman SB (1987) Propionibacterium acnes osteomyelitis: case report and review of the literature. J Clin Microbiol 25:251-254

4. Urquhart DM, Zheng Y, Cheng AC, Rosenfeld JV, Chan P, Liew S, Hussain SM, Cicuttini FM (2015) Could low grade bacterial infection contribute to low back pain? A systematic review. BMC Med 13:13

5. Ganko R, Rao PJ, Phan K, Mobbs RJ (2015) Can bacterial infection by low virulent organisms be a plausible 16 cause for symptomatic disc degeneration? A systematic review. Spine 40:E587-E592

6. Wedderkopp N, Thomsen K, Manniche C, Kolmos HJ, Secher Jensen T, Yde Leboeuf (2009) No evidence for presence of bacteria in Modic type I changes. Acta Radiol 50:65-70

7. de Roos A, Kressel H, Spritzer C, Dalinka M (1987) MR imaging of marrow changes adjacent to end plates in degenerative lumbar disk disease. Am J Roentgenol 149:531-534

8. Modic MT, Steinberg PM, Ross JS, Masaryk TJ, Carter JR (1988) Degenerative disk disease: assessment of changes in vertebral body marrow with MR imaging. Radiology 166:193-199

9. Brinjiki W, Diehn F, Jarvik J, Carr C, Kallmes D, Murad M et al (2015) MRI findings of disc degeneration are more prevalent in adults with low back pain than in asymptomatic controls: a systematic review and meta-analysis. Am J Neuroradiol 36(12):2394-2399

10. Zhang YH, Chang-Zhao CQ, Jiang LS, Chen XD, Li-Yang Dai LY (2008) Modic changes: a systematic review of the literature. Eur Spine J 17:1289-1299

11. Jensen TS, Karppinen J, Sorensen JS, Niinimäki J, Leboeuf-Yde C (2008) Prevalence of vertebral endplate signal changes and their association with non-specific low back pain-a systematic literature review. Eur Spine J 17:1407-1422

12. Wang Y, Videman T, Battie MC (2012) Modic changes: prevalence, distribution patterns, and association with age in white men. Spine 12:411-416

13. Kjaer P, Leboeuf-Yde C, Korsholm L, Sorensen JS, Bendix T (2005) Magnetic resonance imaging and low back pain in adults: a diagnostic imaging study of 40-year-old men and women. Spine 30:1173-1180 
14. Kleinstuck F, Dvorak J, Mannion AF (2006) Are "structural abnormalities" on magnetic resonance imaging a contraindication to the successful conservative treatment of chronic nonspecific low back pain? Spine 31:2250-2257

15. Albert HB, Lambert P, Rollason J, Sorensen JS, Worthington T, Pedersen MB, Nørgaard HS, Vernallis A, Busch F, Manniche C, Elliott T (2013) Does nuclear tissue infected with bacteria following disc herniations lead to Modic changes in the adjacent vertebrae? Eur Spine J 22:690-696

16. Albert HB, Sorensen JS, Christensen BS, Manniche C (2013) Antibiotic treatment in patients with chronic low back pain and vertebral bone edema (Modic type 1 changes): a double-blind randomized clinical controlled trial of efficacy. Eur Spine $\mathbf{J}$ 22:697-707

17. Al-Falahi MA, Salal MH, Abdul-Wahab DM (2014) Antibiotic treatment in patients with chronic low back pain and vertebral bone edema (Modic type I changes): a randomized clinical controlled trial of efficacy. Iraqi Postgrad Med J 13:390-397

18. Antibiotic treatment in patients with chronic low back pain and Modic changes: a randomized double-blind placebo controlled trial, clinicaltrials.gov, ID NCT02323412
19. Is antibiotic treatment effective in the management of chronic low back pain? A clinical trial. Trial ID ACTRN12615000958583. https://www.anzctr.org.au/Trial/Registration/TrialReview.aspx?id $=368913$

20. The effect of ciprofloxacin/co-amoxiclav administration during conservative management of patients with herniated lumbar disc on pain severity and patient's satisfaction. Trial ID: ACTRN12613001074785. https://www.anzctr.org.au/Trial/Regis tration/TrialReview.aspx $? \mathrm{id}=365042 \&$ isReview $=$ true

21. Centres for Disease Control and Prevention. http://www.cdc.gov/ features/antibioticresistance/

22. Antibiotics Research UK, http://www.antibioticresearch.org.uk. Treat Antibiotics Responsibly, Guidance, Education, Tools (TARGET), The Royal College of General Practitioners. http:// www.rcgp.org.uk/clinical-and-research/toolkits/target-antibiotics -toolkit.aspx 